\title{
RESIKO KERENTANAN MASYARAKAT PERKOTAAN TERHADAP BAHAYA BANJIR DI KELURAHAN MARGAGIRI, KECAMATAN BOJONEGARA, KABUPATEN SERANG
}

\section{VULNERABILITY RISK OF URBAN COMMUNITY ON FLOOD HAZARD IN MARGAGIRI VILLAGE, BOJONEGARA DISTRICT, SERANG REGENCY}

(disubmit 05 Februari 2020, direvisi 09 Mei 2020, diterima 29 Juni 2020)

\author{
Arta Rusidarma Putra ${ }^{1}$, Silfiana $^{2}$ \\ ${ }^{1}$ Universitas Bina Bangsa \\ Jl. Raya Serang - Jakarta, KM. 03 No. 1B, Panancangan, Kec. Cipocok Jaya, Kota Serang, \\ Banten 42124 Raya Lintas Timur Km. 4 Pandeglang - Banten \\ Corresponding Author: artar.putra@gmail.com \\ ${ }^{2}$ Badan Perencanaan Pembangunan Daerah Provinsi Banten \\ Sukajaya, Kec. Curug, Kota Serang, Banten 42171
}

\begin{abstract}
ABSTRAK
Penelitian ini bertujuan untuk menganalisis kerentanan sosial ekonomi, dan bangunan fisik masyarakat perkotaan terhadap bencana banjir di Kelurahan Margagiri, Kecamatan Bojonegara Kabupaten Serang Provinsi Banten. Metode yang digunakan dalam penelitian ini metode campuran kualitatif dan kuantitatif. Data yang digunakan data primer dan data sekunder. Data primer dikumpulkan dengan observasi langsung di lapangan dan wawancara berstruktur dengan responden yang dipilih secara random dengan teknik simple random sampling. Wawancara dilakukan terhadap 90 kepala rumah tangga dari total populasi 483 kepala rumah tangga. Sedangkan data sekunder diperoleh dari berbagai dokumen dan instansi terkait yang dianggap berkompeten. Hasil penelitian menujukkan bahwa berdasarkan hasil interpolasi kedalaman banjir yang terkena dampak banjir berada di sebagian besar wilayah bagian timur penelitian dengan kedalaman maksimum 1,5 meter. Berbagai faktor yang dapat menyebabkan banjir, seperti kondisi topografi yang lebih rendah, penyempitan sungai, tersumbatnya drainase dan tersumbatnya saluran sungai yang menyebabkan terhambatnya aliran sungai yang mengalir ke outlet utama. Hasil penelitian ini juga menunjukkan bahwa kerentanan sosial ekonomi yang lebih tinggi ditemukan pada tingkat pendidikan dominan yang rendah yaitu tingkat sekolah dasar (SD) $(40,42 \%)$ dan elemen penduduk rentan karena usia lanjut dan anak-anak sebanyak 30,09\%. Sementara itu, temuan penelitian lainnya berkaitan dengah kerentanan fisik, menunjukkan bahwa tingkat kerentanan tinggi aspek fisik sebanyak 32 bangunan, kerentanan tingkat sedang aspek fisik ebanyak 43 bangunan, dan kerentanan tingkat rendah sebanyak 25 bangunan. Serta tingkat kerentanan sedang hingga tinggi didominasi oleh jenis bangunan non tembok.
\end{abstract}

Kata Kunci: Masyarakat Perkotaan, Kerentanan Sosial Ekonomi, Kerentanan Fisik, Bahaya Banjir 


\section{ABSTRACT}

This study aims to analyze the socio-economic and physical building vulnerability of urban community against flooding in Margagiri Village, Bojonegara District, Serang Regency, Banten Province. The method used in this study was a mixture of qualitative and quantitative method. The data used were primary data and secondary data. Primary data were collected by direct observation in the field and structured interviews with respondents randomly selected by simple random sampling technique. Interviews were conducted with 90 heads of households from a total population of 483 heads of households. Meanwhile, secondary data were obtained from various documents of related institutions that is considered to be competent. The results of study showed that based on the results of interpolation the depth of floods affected by flooding was in most of the eastern part of the study with a maximum depth of 1.5 meters. Various factors can cause flooding, such as lower topographic conditions, river narrowing, drainage clogging and blockage of river channels which causes obstruction of river flow flowing to the main outlet. The results of this study also showed that higher socioeconomic vulnerability was found at the low predominant level of education, namely elementary school level (40.42\%) and elements of the vulnerable population due to old age and children as much as $30.09 \%$. Meanwhile, other research findings related to physical vulnerability, showed that the high level of physical aspect vulnerability was 32 buildings, the moderate level of physical vulnerability was 43 buildings, and the low level vulnerability was 25 buildings.

Keywords: Urban community, socioeconomic vulnerability, physical vulnerability, flood hazarrd

\section{PENDAHULUAN}

Kelurahan Margagiri termasuk wilayah dataran aluvial yaitu kawasan budidaya produktif dimana terdapat pemanfaatan lahan oleh manusia untuk pemukiman, perdagangan dan pertanian (Marfai, 2011; Duckers, 2015; Neale and Weir, 2015). Hal ini terbukti dari melimpahnya sumberdaya berupa tanah yang subur, ketersediaan air dan aksesbilitas yang memadai. Berdasarkan hasil observasi langsung terdapat 251.33 Hektar lahan persawahan dan 23.105 Hektar lahan perkebunan.

Namun demikian, dataran aluvial adalah wilayah yang sangat rawan dan berpotensi terjadi bencana banjir yang akan menimbulkan dampak sosial ekonomi yang sangat besar bagi masyarakat yang mengalaminya (Septriyadi and Hamhaber, 2013; Wesli et al., 2013; Zorn et al., 2015; Rachmawati and Budiarti, 2016). Pada awal tahun 2020 ratusan rumah warga terendam banjir (news.detik.com, 2020). Masalah yang ditimbulkan oleh banjir antara lain adalah terganggunya aktivitas sosial dan ekonomi masyarakat akibat tergenangnya ruas akses jalan dan terganggunya kesehatan warga.

Meningkatnya aktivitas manusia di suatu wilayah harus diimbangi dengan tindakan mitigasi bencana guna mengurangi dampak yang ditimbulkan oleh banjir agar lahan dapat dimanfaatkan secara berkelanjutan (Haryani, 2012; Ma'arif et al., 2014; Widianto and Damen, 2014). Menurut UU No. 24 Tahun 
2007 salah satu upaya yang dilakukan masyarakat dalam menanggulangi bencana adalah Mitigasi, yaitu serangkaian upaya untuk mengurangi risiko bencana, baik melalui pembangunan fisik maupun penyadaran dan peningkatan kemampuan menghadapi ancaman bencana. Mitigasi bencana dilakukan sebagai tindakan guna meminimalisir dampak dari bencana yang terjadi, atau usaha-usaha yang dilakukan untuk menekan korban saat bencana terjadi, baik korban jiwa maupun harta benda. Dalam melakukan tindakan mitigasi bencana, langkah awal yang harus dilaksanakan adalah mengadakan kajian resiko bencana terhadap daerah tersebut. Serta ketika menghitung resiko bencana di suatu wilayah, harus mengetahui bahaya (hazard), kerentanan (vulnerability), dan kapasitas (capacity) berdasarkan karakteristik kondisi wilayah tersebut. Tingginya laju urbanisasi berbanding lurus dengan percepatan pembangunan infrastruktur untuk memenuhi kebutuhan penduduk perkotaan. Apabila perkembangan tersebut terus berlanjut seiring dengan peningkatan aktivitas akan berdampak pada meningkatkan kerentanan bencana jika melebihi kapasitas wilayah terhadap perubahan (Genovese, 2006). Salah satu bencana yang sangat berpotensi adalah banjir. Banjir umumnya terjadi pada kawasan dataran banjir, dalam hal ini adalah suatu wilayah berkembang sebagai wilayah perkotaan disebabkan oleh kebutuhan dan melimpahnya ketersediaan sumberdaya air untuk beragam tujuan. Perubahan penggunaan lahan menjadi kawasan terbangun dapat meningkatkan risiko bencana banjir yang disebabkan oleh berubahnya karakteristik run off, dan jalur drainase bagi air (Cahyadi et al., 2011; Cahyadi dkk., 2012). Selain itu, perubahan iklim juga akan memperparah kondisi di mana beberapa tempat mengalami perubahan frekuensi curah hujan (Sene, 2008; Dibyosaputro dkk., 2016). Bencana banjir diukur dengan probabilitas terjadinya kerusakan yang secara umum disebut sebagai risiko banjir, atau dampaknya terhadap masyarakat seperti korban jiwa atau kerusakan material masyarakat (Dewi, 2007).

Kerusakan yang disebabkan oleh banjir adalah cermin dari kurangnya kesiapan bencana dan dampak dari rusaknya tatanan lingkungan. Munculnya masalah ini sebagian besar disebabkan oleh minimnya penyediaan infrastruktur dan kurang matangnya perencanaan pengelolaan wilayah terdampak bencana yang termasuk salah satu elemen beresiko. Elemen berisiko adalah tingkat kemungkinan suatu elemen untuk mengalami dampak bahaya. Elemenelemen tersebut dapat berupa penduduk, bangunan, pelayanan publik, kegiatan ekonomi, dan infrastruktur (Nott, 2006 dalam Wigati, 2008; Marfai and King, 2008; Marfai et al., 2008). Tingkat 
kerugian yang dialami oleh elemen terdampak dengan tingkat keparahan tertentu yang dihasilkan oleh bahaya tertentu disebut kerentanan. Tingkat kerentanan masyarakat terhadap dampak bencana ditentukan oleh beberapa kondisi yaitu kondisi fisik, sosial, ekonomi, lingkungan, dan proses yang berlangsung di dalamnya. Menurut Cutter (1996) dalam Dewi (2007) menjelaskan bahwa potensi bencana suatu wilayah akan berkurang ataupun meningkat bergantung pada kondisi fisik wilayah serta struktur sosial penduduk di wilayah tersebut. Struktur sosial yang dimaksud yaitu berkaitan dengan kearifan lokal dalam menghadapi bencana, respon penduduk dalam mengatasi, pemulihan, dan beradaptasi terhadap bencana. Kerentanan suatu daerah terhadap bencana berkaitan dengan kondisi geografisnya yang dapat diamati dalam Gambar 1.

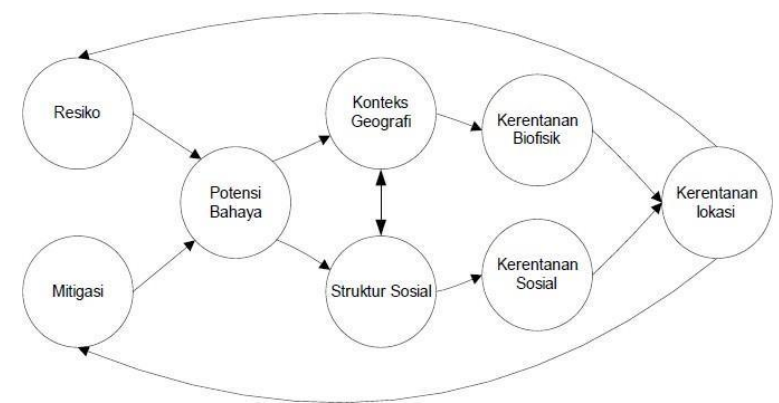

Gambar 1. Model kerentanan terhadap bencana. Sumber : Cutter (1996) dalam Dewi (2007)

Pemetaan terhadap bencana banjir dan pengkajian tentang kerentanan sosial dan fisik pada wilayah berdampak bencana banjir sangatlah penting guna mitigasi untuk menghadapi bahaya banjir, sehingga risiko terhadap bencana bajir dapat dikurangi. Berdasarkan latar belakang tersebut maka penelitian ini bertujuan untuk (1) memetakan bencana banjir di Kelurahan Margagiri, dan (2) menganalisis kerentanan sosial ekonomi masyarakat perkotaan dan fisik terhadap bencana banjir di Kelurahan Margagiri.

\section{METODE PENELITIAN}

Lokasi penelitian dilakukan di Kelurahan Margagiri yang secara yuridis administrasi dan fisik morfologi termasuk wilayah perkotaan yang dikelilingi kawasan perindustrian dan pelabuhan. Kelurahan Margagiri secara administrasi merupakan bagian dari Kecamatan Bojonegara Kabupaten Serang yang terletak pada koordinat UTM 106.0932 5.961.456 dengan luas daerah 3705 Ha. Kelurahan Margagiri berada di sempadan sungai Bogem yang merupakan sungai utama dalam Daerah Aliran Sungai (DAS) Kali Gedong. Kelurahan Margagiri dipilih sebagai wilayah penelitian berdasarkan pertimbangan bahwa wilayah ini sering mengalami kejadian banjir. Selain itu secara geomorfologi wilayah ini terletak di sempadan sungai yang sangat rentan oleh bahaya banjir. Wilayah ini juga merupakan cekungan, sehingga berpotensi 
menjadi pusat larian air dari wilayah di atasnya. Oleh karena itu, BPBD Kabupaten Serang pun menjadikan wilayah ini sebagai daerah rawan banjir seperti gambar berikut:

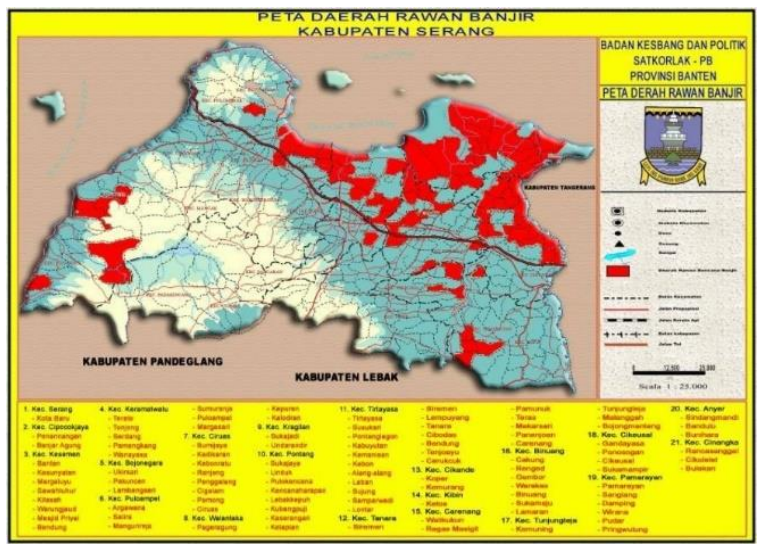

Gambar 2. Peta daerah rawan banjir Kabupten Serang. Sumber : BPBD Kab. Serang

Metode yang digunakan dalam penelitian ini adalah metode campuran kualitatif dan kuantitatif, dengan menggunakan data primer dan data sekunder (Cressw, 2010). Teknik pengumpulan data kualitatif yang merupakan data primer dilakukan dengan cara observasi lapangan. Sedangkan pengumpulan data kuantitatif dengan melakukan wawancara terstruktur terhadap responden dengan menggunakan kuesioner. Selain itu, data sekunder diperoleh dari dokumen-dokumen melalui instansi terkait yang berkompeten. Populasi yang digunakan dalam studi adalah seluruh penghuni bangunan di Kelurahan Margagiri sebanyak 483 rumah tangga yang dikelompokkan dalam tiga tipe golongan struktur bangunan yaitu bangunan tembok, bangunan semi tembok, dan bangunan non tembok. Sampel responden ditetapkan berjumlah 90 rumah tangga yang diambil dengan teknik simple random sampling. Pemetaan banjir dilakukan dengan informasi spasial banjir oleh masyarakat berupa data kedalaman banjir, sebaran wilayah genangan, dan durasi banjir diperoleh dengan melakukan wawancara terhadap masyarakat. Data kedalaman banjir disimbolkan sebagai data titik yang digunakan sebagai data dasar dalam interpolasi wilayah tergenang dengan memanfaatkan software ArcGIS 10.1. Hasil akhir berupa peta bencana banjir. Untuk data yang dikumpulkan dan sumbernya seperti yang disajikan pada Tabel 1.

Tabel 1. Jenis Data Penelitian

\begin{tabular}{|l|l|}
\hline \multicolumn{1}{|c|}{ Jenis Data } & \multicolumn{1}{c|}{ Sumber Data } \\
\hline $\begin{array}{l}\text { DEM (Digital } \\
\text { Evaluation } \\
\text { Model) }\end{array}$ & Observasi Lapangan \\
\hline $\begin{array}{l}\text { Penggunaan } \\
\text { Lahan }\end{array}$ & Data \& Dokumen Kelurahan \\
\hline $\begin{array}{l}\text { Kondisi Sosial } \\
\text { Ekonomi } \\
\text { Masyarakat }\end{array}$ & $\begin{array}{l}\text { Hasil Wawancara dengan } \\
\text { responden }\end{array}$ \\
\hline $\begin{array}{l}\text { Data Curah } \\
\text { Hujan }\end{array}$ & $\begin{array}{l}\text { Badan BMKG Kabupaten } \\
\text { Serang }\end{array}$ \\
\hline
\end{tabular}

\begin{tabular}{|l|l|}
\hline Data Kejadian banjir & BPBD Kabupaten Serang \\
\hline $\begin{array}{l}\text { Data Sebaran, durasi } \\
\text { dan Kedalaman banjir }\end{array}$ & $\begin{array}{l}\text { Observasi Lapangan dan } \\
\text { Wawancara }\end{array}$ \\
\hline $\begin{array}{l}\text { Tingkat Ancaman } \\
\text { elemen berdampak }\end{array}$ & $\begin{array}{l}\text { Observasi Lapangan dan } \\
\text { Wawancara }\end{array}$ \\
\hline
\end{tabular}


Jurnal Kebijakan Pembangunan Daerah, Vol.4, No.1, Juni 2020, Hal. 62-76 p-ISSN: 2597-4971, e-ISSN: 2685-0079

\begin{tabular}{|l|l|}
\hline Data Kejadian banjir & BPBD Kabupaten Serang \\
\hline bencana & dengan informan \\
\hline $\begin{array}{l}\text { Tingkat Kerentanan } \\
\text { Fisik dan Sosial }\end{array}$ & $\begin{array}{l}\text { Observasi Lapangan dan } \\
\text { Wawancara dengan } \\
\text { informan }\end{array}$ \\
\hline
\end{tabular}

Penilaian terhadap kerentanan dilakukan terhadap kondisi sosial ekonomi dan kondisi fisik. Nilai kerentanan secara fisik diukur berdasarkan parameter berupa jenis bangunan, tinggi pondasi bangunan, kedalaman banjir, dan tingkat kerusakan bangunan. Kerusakan yang diamati pada penelitian ini adalah kerusakan pada dinding dan lantai bangunan karena dinding dan lantai pada suatu bangunan merupakan bagian yang mudah mengalami kerusakan saat banjir (Sagala, 2006). Hasil pengolahan diklasifikasikan dalam tiga kelas kerentanan yaitu kerentanan rendah, sedang dan tinggi. Analisis nilai kerentanan sosial ekonomi dilakukan terhadap indikator kerentanan berupa penduduk terpapar dan kelompok rentan. Analisis ini dilakukan berdasarkan data hasil wawancara dengan variabel pendapatan penduduk, komposisi umur penduduk, dan jenis kelamin. Sementara itu, analisis data kuantitatif dengan menghitung frekuensi berupa persentase dari tiap jawaban responden.

\section{HASIL DAN PEMBAHASAN}

\section{Pemetaan Wilayah Banjir}

Kedalaman banjir diklasifikasikan ke dalam tiga kelas yaitu rendah $(0-1$ meter $)$, sedang ( $1-2$ meter), dan tinggi (> 2 meter). Pembagian kelas kedalaman banjir didasarkan atas pengaruh yang ditimbulkan oleh banjir dan tindakan apa yang harus dilakukan masyarakat dalam menghadapinya. Kedalaman banjir yang rendah tidak terlalu membahayakan barang properti yang dimiliki masyarakat, karena sebagian besar bangunan rumah berupa rumah mempunyai tinggi tiang antara 1 sampai 2 meter. Masyarakat dapat bertahan terhadap banjir dengan tingkat kedalaman rendah. Pada saat wawancara dengan masyarakat menyampaikan bahwa kedalaman banjir sedang hingga tinggi dapat mengganggu aktifitas baik dalam kegiatan perekonomian maupun sosial.

Kecepatan aliran air pada saat banjir tidak terlalu cepat. Banjir di wilayah penelitian disebabkan oleh karena banjir kiriman dan hasil dari arus balik Sungai Bogem yang masuk ke Sungai Gedong. Aliran banjir dapat bergerak dengan bebas dan tidak tertahan oleh bangunan karena sebagian besar rumah penduduk berupa rumah dengan pilar-pilar yang tinggi. Durasi banjir rata-rata selama 3 hari. Beberapa penduduk mengungkapkan bahwa wilayah mereka dapat tergenang paling lama hingga 1 minggu. Kondisi ini disebabkan oleh bangunan permukiman penduduk berada 
di wilayah yang berbatasan langsung dengan tubuh air atau berada di wilayah yang selalu tergenang oleh air sepanjang tahun.

Umur bangunan di wilayah penelitian lebih dari 10 tahun. Kondisi ini mengindikasikan bahwa kearifan lokal dalam menghadapi banjir telah berkembang dengan baik berdasarkan pengalaman-pengalaman penduduk dalam menghadapi situasi bencana banjir, sehingga mampu bertahan untuk menetap di wilayah tersebut. Umur bangunan juga berkontribusi terhadap keamanan penduduk dan ketahanan terhadap bahaya banjir. Hal ini bergantung kondisi bangunan itu sendiri dan jenis material yang digunakan. Berdasarkan peta genangan banjir menunjukkan bahwa tidak semua wilayah penelitian mengalami banjir. Banjir tidak terjadi di bagian selatan dan tenggara wilayah penelitian disebabkan wilayah tersebut memiliki elevasi yang lebih tinggi dibanding bagian wilayah lainnya yang diterangkan pada gambar peta genangan banjir. Hal ini sejalan dengan hasil temuan penelitian yang dilakukan Utomo (2012) yang menyebutkan bahwa faktor yang berpengaruh dalam penentuan tingkat kerentanan terhadap bencana banjir diantaranya adalah Aspek Lingkungan: Curah hujan yang tinggi, Jarak dari sungai, Ketinggian Topografi tanah dan penggunaan lahan dan Aspek Fisik: Persentase kerusakan jaringan jalan dan ketinggian kepadatan bangunan seperti disajikan pada Gambar 3.

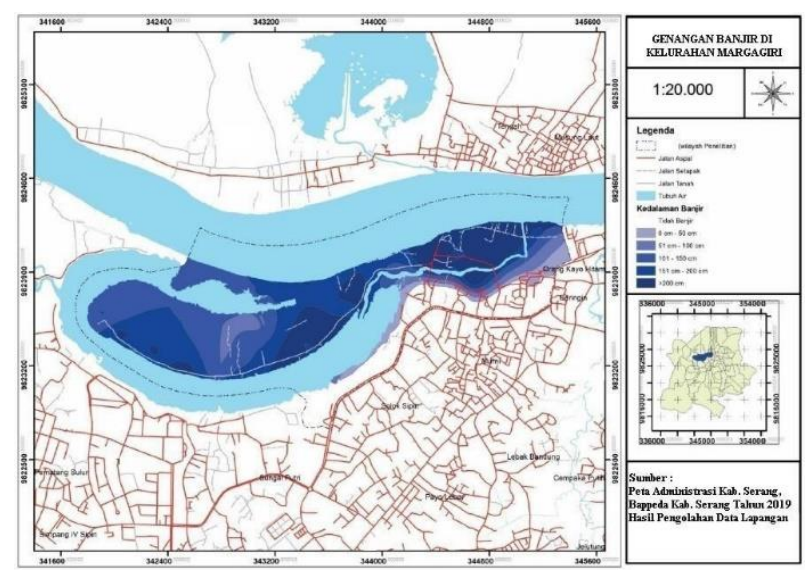

Gambar 3. Peta genangan banjir di Kelurahan Margagiri

\section{Kerentanan Sosial Ekonomi}

Bencana sangat berpotensi terjadi ketika masyarakat menghadapi fenomena bahaya yang melebihi kapasitas masyarakat dalam menghadapi bahaya tersebut. Kerentanan sosial ekonomi berkaitan dengan kemampuan individu atau kelompok orang dalam menanggulangi, bertahan, dan pulih dari dampak kejadian bencana.. Kondisi ini berarti bahwa efek yang ditimbulkan suatu bencana dipengaruhi oleh tingkat kerentanan masyarakat terhadap bahaya (Twigg, 2011). Kondisi sosial ekonomi masyarakat merupakan salah satu aspek kerentanan yang harus dikaji untuk mengetahui tingkat kemampuannya dalam menghadapi bencana. Kerentanan sosial dalam penelitian ini mencakup variabel pendapatan penduduk, jenis kelamin, pekerjaan, dan tingkat pendidikan. 
Hasil penelitian menunjukkan bahwa komposisi umur didominasi oleh penduduk usia produktif (15 - 40 tahun) sejumlah 274 orang $(69,89 \%)$ diikuti oleh penduduk usia muda (0-14 tahun) sejumlah 83 orang $(21,17 \%)$ dan penduduk kelompok usia lanjut sejumlah 35 orang $(8,92 \%)$. Kondisi ini menunjukkan bahwa jumlah penduduk kelompok rentan lebih sedikit dibanding penduduk usia non rentan sehingga penanganan di saat bencana dapat lebih mudah. Faktor gender juga menjadi salah satu elemen yang berpengaruh terhadap munculnya kerugian akibat bencana. Penduduk perempuan lebih rentan terhadap bencana dibanding penduduk laki- laki. Temuan pada penelitian ini sejalan dengan temuan yang dilakukan oleh Twigg (2011) yang menyatakan bahwa berdasarkan data kematian akibat bencana di Bangladesh pada tahun 1991 menunjukkan bahwa angka kematian perempuan berumur sepuluh tahun, tiga kali lebih besar dibanding angka kematian laki-laki pada umur yang sama.

Faktor umur juga merupakan salah satu elemen yang dapat dirugikan oleh kejadian bencana. Penduduk usia lanjut umumnya lebih rentan secara fisik disebabkan oleh faktor kesehatan jangka panjang baik itu masalah kesehatan pernapasan atau kardiovaskular, maupun masalah degradasi indra penglihatan maupun pendengaran (Twigg, 2011). Penduduk dengan usia lanjut, wanita, dan anak-anak perlu mendapat prioritas utama untuk dievakuasi dari wilayah bencana karena merupakan kelompok rentan terhadap bencana. Dalam menanggapi hal ini harus didukung oleh rencana evakuasi yang baik agar proses evakuasi dapat berjalan dengan baik, efektif dan efisien.

Hasil temuan lain dalam penelitian ini adalah sebagian besar kepala rumah tangga di Kelurahan Margagiri berada di usia produktif dengan umur 30 - 40 tahun sebesar $30 \%, 40$ - 50 tahun sebesar 32\%, dan kepala rumah tangga berusia lanjut (> 50 tahun) sebesar $27 \%$, sedangkan berusia muda ( $<30$ tahun) sebesar $11 \%$. Kepala keluarga memiliki peranan sangat penting dalam ketahanan menghadapi bencana. Sebagai pengelola dan pemimpin rumah tangga harus mempunyai kecakapan dalam situasi apapun baik di waktu sebelum maupun di saat bencana karena kepala rumah tangga pria dianggap memiliki kelebihan dalam pembagian tugas dalam keluarga. Dalam rumah tangga di mana kepala keluarga adalah pria, sedangkan wanita adalah menunggu keputusan kepala keluarga mengenai tindakan apa yang akan diambil untuk menghadapi bencana. Sedangkan kepala keluarga wanita lebih rentan di mana 
mereka harus mempersiapkan segala sesuatu sendiri. Selain itu kepala keluarga wanita akan kesulitan untuk memperoleh bantuan dalam kondisi yang kacau saat terjadi bencana (Twigg, 2011).

Data hasil penelitian menunjukkan bahwa jumlah anggota keluarga dalam satu rumah bervariasi dengan anggota 4 6 orang mendominasi dengan jumlah terbanyak, diikuti oleh kelompok keluarga dengan jumlah $>6$ orang, dan 0 - 3 orang anggota keluarga. Penyebab besarnya jumlah anggota keluarga oleh satu rumah adalah ditempati oleh lebih dari satu kepala keluarga. Pasangan penduduk yang baru menikah masih menempati rumah orang tua dan hidup bersama. Besarnya jumlah anggota keluarga juga dapat membantu ketika terjadi bencana, sebab anggota keluarga dapat menjadi tenaga kerja tambahan apabila pekerjaan utama tidak dapat memberikan penghasilan yang mencukupi.

Hasil penelitian selanjutnya adalah tingkat pendidikan penduduk di wilayah penelitian didominasi Sekolah Dasar (SD) sebanyak 40,42\%, diikuti oleh Sekolah Menengah Atas (SMA) sebanyak 33,43\%, Sekolah Menengah Pertama (SMP) sebanyak $15,52 \%$ dan perguruan tinggi sebanyak $10,63 \%$. Tingkat pendidikan yang rendah menyebabkan penduduk tidak banyak memiliki pilihan pekerjaan yang dapat dilakukan serta berakibat pada sulitnya meningkatkan kualitas hidup penduduk, di mana penduduk tidak memiliki kecakapan yang baik untuk meningkatkan pendapatannya melalui pekerjaan yang baik pula.

Sebagian besar penduduk bermatapencaharian sebagai pegawai swasta (45\%) diikuti dengan wirausaha (36\%). Pekerjaan sebagian besar merupakan pegawai swasta di mana penduduk bekerja pada perusahaan swasta baik di bidang manufaktur, jasa maupun perdagangan. Penduduk yang mempunyai pekerjaan tetap memiliki kerentanan yang rendah, karena dengan penghasilan tetap dapat diandalkan untuk memenuhi pengeluaran pasca bencana. Penduduk dengan pendapatan yang tinggi juga tidak terlalu rentan dan terpengaruh oleh kejadian banjir karena dengan penghasilan tinggi cenderung memiliki tabungan yang mampu memberikan ketahanan finansial dalam menghadapi seluruh pengeluaran ekonomi di saat pra dan pasca kejadian banjir. Sedangkan penduduk dengan pendapatan menengah termasuk kategori dengan tingkat kerentanan sedang, namun demikian kondisi penduduk ini masih lebih baik dibandingkan penduduk dengan pendapatan rendah. Dengan kata lain kesejahteraan masyarakat sangat berperan dalam kerentanan terhadap bencana banjir. 
Ini juga sejalan dengan hasil penelitian Danianti (2015) yang menyatakan bahwa masyarakat yang sudah mampu menyisakan pendapatan yang dihasilkan memiliki skor yang lebih tinggi dibandingkan dengan masyarakat yang belum bisa menyisakan pendapatannya, karena kapasitas adaptasi yang dimiliki juga lebih tinggi dalam menghadapi kondisi yang tidak terduga akibat bencana banjir yang terjadi.

Analisis data satelit Google Earth menunjukkan bahwa ekosistem mangrove di Kabupaten Tengarang secara umum dalam kondisi yang memprihatinkan. Dari panjang pantai sekitar $51,20 \mathrm{~km}$, tidak ditemukan adanya ekosistem mangrove yang masif dan luas. Komunitas mangrove dengan luas terbesar hanya terdapat di Desa Pagedangan Ilir Kecamatan Kronjo pada koordinat (titik tengah) $6^{\circ} 02$ ' $15^{\prime \prime} \mathrm{LS}$ - 106 $27^{\circ} 14^{\prime \prime}$ BT dengan luas hanya sekitar 3,87 ha. Sisanya, ekosistem mangrove tersebar dalam unit-unit komunitas yang kecil-kecil.

Ada satu hal yang cukup menarik dari hasil analisis data satelit tersebut, yaitu bahwa kegiatan reboisasi mangrove pada pematang-pematang tambak telah terlihat berhasil di banyak lokasi di Kabupaten Tangerang. Hal ini menunjukkan adanya keseriusan dari pemerintah daerah dan seluruh pihak dalam melakukan gerakan penghijauan wilayah pesisir di Kabupaten Tangerang.

\section{Kerentanan Fisik}

Kerentanan fisik dilakukan pemetaan terhadap 90 sampel di wilayah penelitian. Jenis konstruksi/material fisik bangunan merupakan salah satu faktor yang mempengaruhi mudahnya suatu bangunan mengalami kerusakan (Guarin, 2003). Jenis bangunan yang diteliti dalam penelitian ini adalah bangunan non tembok, semi tembok, dan tembok seperti ditunjukkan pada Gambar 4.

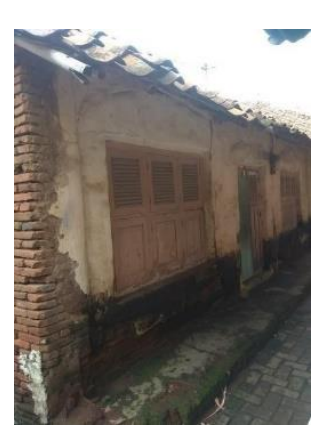

(a)

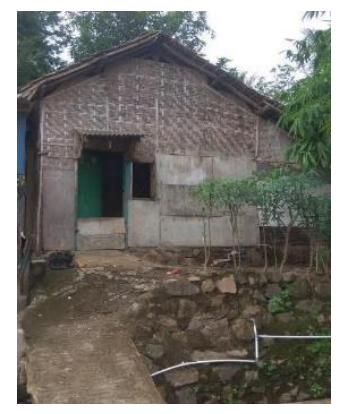

(b)

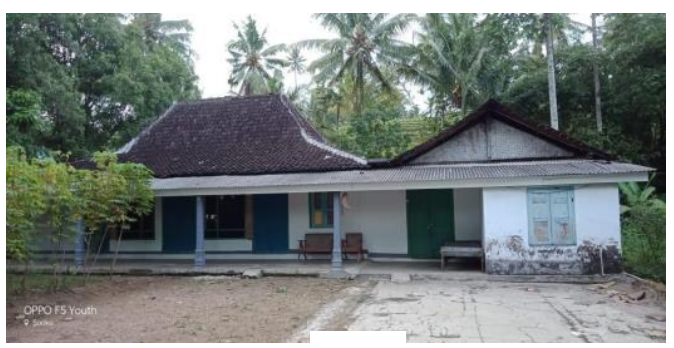

(c)

Gambar 4. Beberapa jenis Bangunan di daerah penelitian (a) Bangunan Non Tembok, (b) Bangunan Semi Tembok, (c) Bangunan Tembok

Jenis bangunan non-tembok adalah bangunan berupa kayu/papan. Jenis bangunan semi tembok merupakan 
campuran antara beton dengan kayu.

Sedangkan jenis bangunan tembok terbuat dari beton dengan kombinasi bahan yaitu batu bata, semen, dan pasir. Kerusakan yang diamati dalam penelitian ini adalah kerusakan yang terdapat pada dinding dan lantai bangunan. Selain itu, tinggi pondasi bangunan juga merupakan salah satu variabel untuk menentukan kerentanan fisik. Tinggi pondasi bangunan rata-rata untuk bangunan non tembok adalah 150 $\mathrm{cm}$, bangunan semi tembok $180 \mathrm{~cm}$, dan bangunan tembok $200 \mathrm{~cm}$. Kedalaman rata-rata banjir di wilayah penelitian adalah $150 \mathrm{~cm}$. Data tinggi pondasi bangunan sangat beragam antara 0 hingga $250 \mathrm{~cm}$. Pengukuran tinggi pondasi bangunan rumah lokasi penelitian diklasifikasikan dalam tiga kelas (Tabel 2). Berdasarkan penelitian menunjukkan bahwa tingkat kekuatan bangunan untuk bertahan terhadap banjir untuk masingmasing kategori bangunan disajikan pada Tabel 3.

Tabel 2. Kelas tinggi pondasi bangunan

\begin{tabular}{|c|c|c|c|}
\hline Kategori & $\begin{array}{c}\text { Ketinggian } \\
\text { Pondasi }\end{array}$ & Jumlah & $\%$ \\
\hline Rendah & $0-100 \mathrm{~cm}$ & 40 & $44,44 \%$ \\
\hline Sedang & $101-200 \mathrm{~cm}$ & 44 & $48,88 \%$ \\
\hline Tinggi & $>200 \mathrm{~cm}$ & 6 & $6,68 \%$ \\
\hline Jumlah & 90 & $100 \%$ \\
\hline
\end{tabular}

Sumber : Pengolahan Data Primer
Tabel 3. Kerentanan jenis bangunan

\begin{tabular}{|c|c|c|c|}
\hline No & $\begin{array}{c}\text { Jenis } \\
\text { Bangunan }\end{array}$ & Kerentanan & $\%$ \\
\hline 1 & Non Tembok & Tinggi & $48,12 \%$ \\
\hline 2 & Semi Tembok & Sedang & $5,32 \%$ \\
\hline 3 & Tembok & Rendah & $46,56 \%$ \\
\hline \multicolumn{3}{|c|}{ Jumlah } & $100 \%$ \\
\hline
\end{tabular}

Sumber : Pengolahan Data Primer

Kerentanan fisik diperoleh dengan menumpang susunkan antara peta jenis struktur bangunan dengan tinggi pondasi bangunan. Klasifikasi tingkat kerentanan fisik dilakukan dengan metode matriks berdasarkan aturan Badan Nasional Penanggulangan Bencana (BNPB). Klasifikasi kerentanan fisik dibagi dalam tiga kelas yaitu kerentanan rendah, sedang dan tinggi. Matriks klasifikasi kerentanan fisik struktur bangunan dapat dilihat pada Tabel 4. Hasil tumpang disusun antara peta jenis bangunan dan peta tinggi pondasi bangunan menghasilkan tingkat kerentanan struktur bangunan.

Tabel 4. Kelas kerentanan fisik bangunan

\begin{tabular}{|c|c|c|c|c|}
\hline \multirow{3}{*}{$\begin{array}{c}\text { Jenis } \\
\text { Banguna } \\
\mathrm{n}\end{array}$} & $\begin{array}{c}\text { Kerentanan } \\
\text { Fisik }\end{array}$ & \multicolumn{3}{|c|}{ Tinggi Pondasi Bangunan } \\
\cline { 2 - 5 } & Rendah & Rendah & Sedang & Tinggi \\
\cline { 2 - 5 } & Sedang & Rendah & Rendah & Sedang \\
\cline { 2 - 5 } & Tinggi & Sedang & Tinggi & Tinggi \\
\hline
\end{tabular}

Sumber : Pengolahan Data Primer 


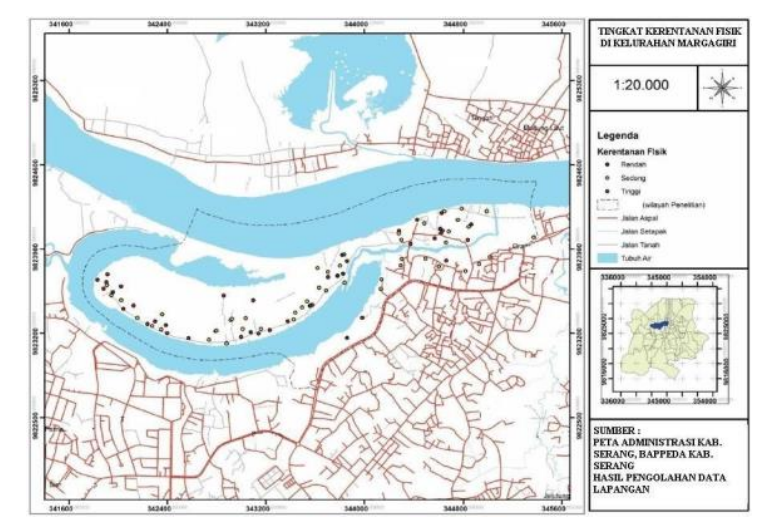

Gambar 5. Tingkat kerentanan fisik lokasi penelitian

Berdasarkan Gambar 5 dapat dianalisis bahwa sebaran kelas kerentanan tinggi terkonsentrasi di bagian timur wilayah penelitian, sedangkan kelas kerentanan sedang dan rendah tersebar merata di seluruh wilayah penelitian. Peta hasil tumpang disusun menunjukkan bahwa kerentanan fisik di lokasi penelitian didominasi oleh kelas sedang $(27,10 \%)$, diikuti kelas tinggi $(46,28 \%)$, dan kelas rendah (26,62\%). Sebaran kelas kerentanan tinggi terkonsentrasi di bagian timur wilayah penelitian, sedangkan kelas kerentanan sedang dan rendah tersebar merata di seluruh wilayah penelitian. Jenis bangunan di bagian timur umumya berupa bangunan non tembok dengan tinggi pondasi sedang $(101 \mathrm{~cm}-200 \mathrm{~cm})$, sehingga bangunan di wilayah ini lebih rentan terhadap banjir.

\section{KESIMPULAN}

Berdasarkan hasil penelitian ini dapat disimpulkan bahwa hasil interpolasi kedalaman banjir di Kelurahan Margagiri menunjukkan bahwa sebagian besar wilayah penelitian terkena dampak banjir dengan kedalaman maksimum mencapai 2 meter di bagian timur wilayah penelitian. Hal ini disebabkan oleh berbagai faktor, seperti kondisi topografi yang lebih rendah dibandingkan wilayah lainnya, terjadi penyempitan sungai dan penyumbatan saluran sungai, sehingga menghambat air untuk tersalurkan ke outlet utama.

Sementara itu berdasarkan analisis kerentanan fisik, maka penelitian ini menyimpulkan bahwa tingkat kerentanan fisik tinggi ditemukan sebanyak 32 bangunan, kerentanan fisik sedang sebanyak 43 bangunan, dan kerentanan rendah sebanyak 25 bangunan. Tingkat kerentanan sedang hingga tinggi mendominasi wilayah penelitian karena jenis bangunan berupa bangunan non tembok. Kerentanan sosial ekonomi lebih tinggi ditemukan pada elemen tingkat pendidikan dengan sebagian besar tingkat pedidikan rendah yaitu SD $(40,42 \%)$ dan elemen penduduk rentan karena usia lanjut dan anak-anak sebanyak 30,09\%. 


\section{REKOMENDASI}

Berdasarkan hasil kesimpulan dan temuan dalam penelitian ini, maka dapat diusulkan beberapa rekomendasi sebagai berikut:

1. Meningkatkan fungsi kawasan lindung guna mengontrol dalam perkembangan tata guna lahan.

2. Berperan aktif dalam upaya nonstruktural yang dapat dilakukan dengan cara sosialisasi pengetahuan mengenai karakteristik bencana banjir dan pelatihan kepada masyarakat mengenai apa saja langkah dalam menghadapi bencana banjir serta perlu dilakukan simulasi proses evakuasi sehingga masyarakat dapat menyadari berbagai langkah yang harus diambil dalam menghadapi bencana banjir. Saat ini memang sudah dilakukan upaya non-struktural tersebut, namun belum semua masyarakat memahami karakteristik bencana banjir karena upaya yang dilakukan belum mencangkup seluruh lapisan masyarakat.

3. Masyarakat lokal harus proaktif dan memenuhi kebijakan dan rencana terkait mitigasi bencana dalam menghadapi resiko bencana banjir. Tanpa sikap tersebut, kebijakan dan rencana mitigasi bencana akan sulit untuk diimplementasikan

4. Masyarakat lokal harus mengadakan forum pengurangan resiko bencana. Saat ini sudah terdapat lembaga atau forum pengurangan resiko bencana banjir, namun masih belum maksimal perannya dalam masyarakat sehingga masih banyak masyarakat yang belum memahami dengan pasti karakteristik bencana banjir yang mengancam mereka.

\section{DAFTAR PUSTAKA}

Cahyadi, A., Priadmodjo, A. \& Yananto, A. 2011. Criticizing The Conventional Paradigm of Urban Drainage. Proceeding The 3rd International Graduated Student Conference on Indonesia. Yogyakarta: Sekolah Pascasarjana Universitas Gadjah Mada.

Cahyadi, A., Yananto, A., Wijaya, M.S., \& Nugraha, H. (2012). Analisis Perubahan Penggunaan Lahan Terhadap Retensi Potensial Air oleh Tanah pada Kejadian Hujan Sesaat (Studi Kasus Perubahan Penggunaan Lahan di DAS Garang Jawa Tengah). Prosiding Seminar Nasional Informatika. Yogyakarta: Jurusan Informatika, UPN "Veteran" Yogyakarta.

Creswell, J.W 2010. Research Design: Pendekatan Kualitatif, Kuantitatif, 
dan Mixed. Pustaka Pelajar, Yogyakarta.

Danianti, R.P. \& Sariffuddin.. 2015. Tingkat Kerentanan Masyarakat Terhadap Bencana Banjir di Perumnas Tlogosari, Kota Semarang. Jurnal Pengembangan Kota, 3(2), 9099.

Dewi, A. 2007. Community Based Analysis of Coping With Urban Flooding : a Case Study in Semarang, Indonesia. ITC, International Institute for Geo-Information Science, MSc Thesis, Enschede, The Netherland.

Dibyosaputro, S., Cahyadi, A., Nugraha, H. \& Suprayogi, S. 2016. Estimasi Dampak Perubahan Iklim Terhadap Kerawanan Banjir Lahar di Magelang, Jawa Tengah. Prosiding Seminar Nasional Geografi UMS 2016. Surakarta: Universitas Muhammadiyah Surakarta.

Duckers, M., Frerks. G. \& Birkmann, J. 2015. Exploring the Plexus of Context and Consequences : An Empirical Test of A Theory of Disaster Vulnerability. International Journal of Disaster Risk Reduction, 13, 85-95.

Genovese, E. 2006. A Methodological Approach to Land Use-Based Flood Damage Assessment in Urban Areas: Prague Case Study. Institute for Environtmental Study

Haryani. 2012. Model Mitigasi Bencana di Wilayah Pesisir Dengan Pemberdayaan Masyarakat. Tata Loka, 14(3), 201-212.

Ma'arif, S., Damayanti, F., Suryanti, E.D., \& Wicaksono. A.P. 2014. Initiation of Desa Tangguh Bencana Through Stimulus-Response

Method.
Indonesian Journal of Geography, 44(2), 173-182

Marfai, M.A., \& King, L. 2008. Potential Vulnerability Implication of Coastal Inundation Due to Sea Level Rise for The Coastal Zone of Semarang City, Indonesia. Environmental Geology, $54,1.235-1.245$.

Marfai, M.A., L. King, L., Sartohadi, J., Sudrajat, Budiani, S.R. \& Yulianto, F. 2008. The Impact of Tidal Flooding on a Coastal Community in Semarang, Indonesia. Environmentalist, 28, 237-248. Marfai, M.A. (2011). The Hazard of Coastal Erosion in Central Java Indonesia: An Overview. Geografia Online (3): 1-9.

Neale, T. \& Weir, J.K. 2015. Navigating Scientific Uncertainty in Wildfire and Flood Risk Mitigation : A Qualitative Review. International Journal of Disaster Risk Reduction 13: 255-267.

Rachmawati, R. \& Budiarti, C.V. 2016. Use of Space the Need For Planning in the Disaster- Prone Area of Code River, Yogyakarta, Indonesia. Indonesian Journal of Geography, 48 (2), 178-190.

Sagala, S., Pratama, A.A. Argo, T.A. \& Asirin. 2012. Peran Remitan Tenaga Kerja Indonesia Terhadap Potensi Pengurangan Risiko Bencana Banjir di Wilayah Perkotaan Indramayu. Tata Loka, 14(1), 37-51.

Sakijege, T. 2013. Managing Flood Risks : Lessons From Keko Machungwa Informal Settlement in Dares Salaam, Tanzania. Indonesian Journal of Geography, 45(1), 1-14 
Sene, K. 2008. Flood Warning, Forecasting, and Emergency Responce. Springer.

Septriadi, R. \& Hamhaber, J. 2013. Hazard Assesment to Tidal Flood Inundation (Case Study : Tegal Municipality). Indonesian Journal of Geography, 45(1), 24-37

Taylor, H. \& Peace, R.. 2015. Children and Cultural Influence in A Natural Disaster, Flood Response in Surakarta, Indonesia. International Journal of Disaster Risk Reduction, 13, 76- 84 .

Twigg, J. 2011. Disaster Risk Reduction, Mitigation and Preparedness in Development and Emergency Programming. London: ODI.

Ullah, R., Shivakoti, G.P. \& Ali, G. 2015. Factors Affecting Farmers'Risk Attitude and Risk Perception : The Case of Khyber Pakhtunkhwa, Pakistan. International Journal of Disaster Risk Reduction, 13, 151157.

Utomo, B.B. \& Supriharjo, R.D. 2012. Pemintakatan Risiko Bencana Banjir Bandang di Kawasan Sepanjang Kali Sampean, Kabupaten Bondowoso. Jurnal Teknik ITS, $1(1)$, 58- 62 .

Wesli, Sirojuzilam, Matondang, A.R., Lubis, S. 2013. The Effect of Land Use and Community Participation on Flood Control at North Aceh District. Indonesian Journal of Geography 45, (2), 171-186.

Widianto, A. \& Damen, M. (2014). Determination on Coastal Belt in the Disaster Prone Area : A Case Study in the Coastal Area of Bantul Regency, Yogyakarta, Indonesia. Indonesian Journal of Geography, 46(2), 125-137.
Wigati, M. 2008. Improving Flood Hazard and Vulnerability Assessment Based on Social Assessment In Bogowonto River. MSc Thesis. Enschede, The Netherland: ITC, International Institute for Geo-Information Science.

Zorn, C., Asaad \& Shamseldin Y. 2015. Post-Disaster Infrastructure Restoration : A Comparison of Events For Future Planning. International Journal of Disaster Risk Reduction, 13, 158-166.

Undang-undang Republik Indonesia No. 24 tahun 2007 tentang Penanggulangan Bencana.

https://bantenhits.com/2020/01/07/kalibogem-meluap-ratusan-rumah-didesa-bojonegara-dan-margagiriterendam-banjir/

https://bpbd.bantenprov.go.id/upload/deni /foto/Kab.\%20Serang\%20(Rawan\% 20Banjir).jpg

https://news.detik.com/berita/d4849661/banjir-rendam-ratusanrumah-di-bojonegara-serang

http://prodeskel.bantenprov.go.id/index.p hp/home/kecamatan/72

https://www.radarbanten.co.id/intensitashujan-tinggi-bpbd-kabupatenserang-tingkatkan- kewaspadaan/ 